\title{
ACCENT: a pan-European co-created tool to take refurbishment decisions at a city scale based on buildings' energy performance
}

\author{
V. Valero ${ }^{1}$, M. Navarro ${ }^{1}$, C. Mateo ${ }^{1} \&$ S. Tesseron-Stevelinck ${ }^{2}$ \\ ${ }^{1}$ Valencian Institute of Building, Spain \\ ${ }^{2}$ Research and Technology Division, CRIGEN, ENGIE, France
}

\begin{abstract}
The public sector is an important driver in supporting market transformation towards more efficient energy systems and buildings. To succeed in the energy transition it is important not only to mobilise local administrations, but also to engage citizens, and companies developing their business in the sector, in public energy planning and policy. But the development, financing and implementation of ambitious sustainable energy plans and measures should be based on reliable data.

The aim of this paper is to present the main insights of ACCENT, a new decision-support tool for local administrations developed under a pan-European project upheld by Climate KIC. ACCENT tool is based on a web-platform that allows local administrations to define and monitor measures addressed to improve the energy performance of buildings included in their sustainable energy action plans. The research has allowed us to recognize common pan-European challenges as the need to share real energy consumption data of buildings or the low willingness of some energy suppliers to offer information in this regard. In addition, we face specific local barriers based mainly on the lack of linkage among public bodies, the dispersion of data, the requirement of legislative and disseminating mechanisms to make citizens aware of energy renovation of their own buildings, or the inaccessibility to existing information on the state of the buildings as IEE database (Buildings Evaluation Report) in the case of Spain. In conclusion, ACCENT allows local administrations to take refurbishment decisions at a city scale based on the energy performance of buildings.

Keywords: energy strategy, GIS, co-created tool, decision support tool, energy action plan, city ecosystem, energy transition, buildings, energy performance.
\end{abstract}




\section{Introduction}

Cities are completely aware of their key role regarding the energy transition which will occur in the years to come $[1,2]$. Many European cities have long recognised their contribution to climate change and, their potential to be part of the solution. They have launched initiatives that aim at defining local energy strategies integrating economic and environmental issues. These initiatives echo the EU ambition to develop a competitive low carbon economy [3].

In the last years, city energy planning has spread in Europe. Many important networks, such as the Covenant of Mayors (CoM) or the Local Governments for Sustainability (ICLEI) are leading the way towards sustainability and resilience to climate change. The CoM, a major European movement involving local and regional authorities, has gathered more than 6600 European signatory cities as of April 2016 [4]. These signatories voluntarily agree to reduce their $\mathrm{CO}_{2}$ emissions by at least $20 \%$ by 2020 with respect to a baseline emission inventory (BEI), a quantification of the amount of $\mathrm{CO}_{2}$ emitted due to energy consumption in the territory of the signatory within a given period of time, 1990 being the recommended base year. After establishing the BEI, they have to submit a sustainable energy action plan (SEAP) outlining how they intend to reach this $\mathrm{CO}_{2}$ reduction target by 2020, identifying the activities and measures planned, together with time frames and assigned responsibilities.

SEAPs comprise actions in different key target sectors such as buildings, including new buildings and refurbishment of existing ones; municipal infrastructure; land use and urban planning; usage of renewable energy sources; public and private transport policies and urban mobility; citizen and, in general, civil society participation; and information and communication technologies (ICT) [5]. A successful SEAP requires relying on a relevant and detailed diagnosis of their territory, identifying potentials for energy savings and renewable resources and building appropriate mid and long-term strategies that integrate the whole energy value-chain (production, distribution and uses). The collection of reliable data with an acceptable level of accuracy is one of the most difficult tasks in designing, implementing and monitoring a SEAP [6].

Therefore, there is an urgent need to provide local authorities with tools to build up and update a realistic monitoring of the current situation [7, 8]. From there, they will be able to set up targets and evaluate the impact of actions on energy and $\mathrm{CO}_{2}$ reduction. To reach these targets they need to design an action plan together with a follow up instrument, and then mobilize all the city stakeholders (service providers such as network operators, ESCOs, construction and refurbishment companies, renewable energy developers, utilities, energy consultancy companies, urban planners, building construction materials' suppliers; and citizens) around the action plan.

The engagement of all the city stakeholders in the action plan is essential to ensure the energy transition succeeds. This collaborative approach allows service providers and citizens to play an effective role in planning and decision-making processes $[9,10]$. 
Hence, how to drive cities in the development and implementation of their SEAPs involving the interests of different stakeholders? The ACCENT project is a European project co-funded by Climate-KIC aiming at supporting European cities to develop their energy strategy regarding one of the key sectors included in SEAPs: buildings. Buildings are responsible for approximately $40 \%$ of the primary energy consumption in Europe and often they are the largest energy consumer and $\mathrm{CO}_{2}$ emitting source in cities. Therefore, there is a vital need to reduce energy consumption in this sector through efficient policies and innovative solutions [6].

The main result of the project is a co-created tool that pretends to support different stakeholders (local authorities, service providers and citizens) to overcome the barriers they face and to tackle their main needs when implementing energy efficiency building measures at building, district or city scale. This paper presents both, the main insights of the stakeholder's participatory process and the functionalities that ACCENT tool includes, after this co-creation process.

\section{Methods}

\subsection{What is missing? Having a clear overview of the existing tools and markets at European level}

Before starting to develop the ACCENT tool, a preparatory scanning was carried out. This scanning was subdivided in two different tasks, a competitive analysis and a market research.

The competitive analysis was developed in 9 different countries: France, Germany, Italy, Spain, Switzerland, the United-Kingdom, Belgium, the Netherlands and Denmark. The 9 main initiatives in these countries were analysed according to the following criteria with the aim of having a clear overview of the existing similar tools or research programmes: accuracy of data inputs, characterization and visualization of the outputs, interaction among end-users, price.

The competitive analysis was completed with a market research consisting of a set of 103 semi-structured interviews with potential users of the tool in the 9 same countries. 541 of which were made to local authorities, mainly from the CoM network; while the remaining 59 were made to service providers such as network operators, ESCOs, construction and refurbishment companies, renewable energy developers, utilities, energy consultancy companies, urban planners or building construction materials' suppliers. This market research was focused on collecting needs from local authorities and services providers when defining and implementing their energy strategy and also, on gathering their opinion regarding a tool of such characteristics. In parallel, the market research was used to detect if local authorities and services providers were using tools such as those identified in the competitive analysis and how these met, partially met, or does not meet their specific needs.

Both competitive analysis and market research allowed us to identify and rank the potential markets for the ACCENT tool according to the market size and the maturity of the energy planning market in the 9 different countries. 


\subsection{Are these available tools matching the demand side in every country? Validating potential markets for the ACCENT tool: a demonstration phase in 3 specific pilot cases}

After the research was completed and potential markets for ACCENT tool recognised, there was a need to validate this demand deeper with local authorities and service providers from those countries that had been identified as the best markets to introduce ACCENT tool. With this aim 5 structured workshops were held involving local authorities and service providers from Italy, Spain and France.

The goal of these workshops was to validate the value proposition of ACCENT with respect to the needs and barriers for local authorities and service providers and to identify the main challenges for the tool.

The starting point of the workshops were the results of the interviews made in the previous stage to make participants react to these results and to validate or invalidate them. In the second part of the workshops, a mock-up of the ACCENT tool was presented to participants in order to obtain their feedback about it.

These participative workshops provide us with specific information in order to refine and adapt the ACCENT tool to the specific needs of stakeholders in selected countries. Once the mock-up of the ACCENT tool was refined and adapted, we went through an end-user oriented demonstration phase involving 4 different pilot cases: Paris, Valencia, Reggio Emilia and Ferrara. This pilot phase aimed at achieving on the one hand a user-oriented tool for pilot cities and on the other hand, a user-oriented tool for cities ecosystem: service providers and citizens.

The work with cities consisted of 5 semi-structured meetings with the cities representatives. These meetings were focused on managing and guiding them to test the proof-of concept of the tool and analyse their suggestions of improvements regarding functionalities and ergonomics to iterate toward the final tool.

In parallel, the needs of the cities ecosystem (service providers and citizens) were studied. Firstly, we developed a workshop with service providers in each pilot city to go further in their needs/expectations/barriers. With respect to citizens, the process consisted of interviews with citizen representatives (consumers, homemakers and other citizens' associations) in order to obtain information about which are the needs or expectations of citizens regarding energy saving and efficiency in their cities and buildings.

This participatory process allowed us to determine functionalities that should be integrated into ACCENT tool since they try to overcome barriers identified and respond to the needs of all stakeholders involved.

\subsection{How ACCENT tool matches the needs and overcome the barriers identified: defining specific functionalities}

Conclusions of the second phase process were converted into a list of functionalities. The functionalities integrated into ACCENT tool were selected according to the following criteria: their response to specific demands and barriers identified, common interest of all stakeholders involved in the pilot cases, availability of data, and technical feasibility. 


\section{Results}

\subsection{A clear overview of the existing tools and markets at European level}

Through competitive analysis, we identified that different tools are already available in the market or under development, offering some of the services that the ones foreseen for ACCENT. However, it is still a market in its early stages of the lifecycle of the sector. After reviewing 40 initiatives, several weak points were identified:

- $\quad$ Planning studies are usually at the city scale and are mainly paper studies with no interactivity or possibilities to make modifications, with no particular focus on the building stock.

- Most of the tools base totally or mainly its calculations only on statistical data using energy consumptions aggregated and approximated values.

- There is a lack of tools providing urban energy planning assistance and gathering on the same platform the main actors involved in energy efficiency: citizens, municipalities and service providers.

- None of the online platforms providing global estimations or maps of the energy consumption offers a networking option for now to connect with other cities.

These observations have constituted the main drivers to define the ACCENT approach. The research has highlighted the potential innovation opportunity for the development of a co-created support tool to help different stakeholders (cities, services providers and citizens) to take refurbishment decisions based on buildings energy performance.

Furthermore, the market research based on interviews with local authorities and services providers allowed us to identify France, Italy and Spain as potential markets for the introduction of ACCENT tool. The selection of these potential markets were made according to the following requirements: availability of a basic set of data for energy calculation, few competitors, the involvement of local authorities in energy planning and the willingness of service providers to use a tool of these characteristics.

\subsection{Potential markets for the ACCENT tool: a demonstration phase in 3 specific pilot cases}

Hereafter the needs and barriers identified during the demonstration phase of the project are presented. They result from meetings, workshops and interviews held with local authorities, service providers and citizens' representatives. 
Table 1: $\quad$ Main actors' needs identified.

\begin{tabular}{|l|c|c|c|}
\hline \multicolumn{1}{|c|}{ NEEDS } & $\begin{array}{c}\text { Local } \\
\text { admin }\end{array}$ & $\begin{array}{c}\text { Service } \\
\text { providers }\end{array}$ & Citizens \\
\hline Visualization of energy data. & $\mathrm{X}^{1}$ & $\mathrm{X}^{2}$ & $\mathrm{X}^{3}$ \\
\hline Follow-up instrument for action plan. & $\mathrm{X}^{4}$ & & \\
\hline $\begin{array}{l}\text { Decision-support tool for energy } \\
\text { planning (based on different scenarios) }\end{array}$ & $\mathrm{X}^{5}$ & & \\
\hline Learn from other similar experiences. & $\mathrm{X}^{6}$ & & \\
\hline Establishing links with other actors. & $\mathrm{X}^{7}$ & $\mathrm{X}^{8}$ & $\mathrm{X}^{9}$ \\
\hline
\end{tabular}

\subsubsection{Visualization of energy data}

1. Local Administrations: Energy consumption and $\mathrm{CO}_{2}$ emission reductions are both very high on political agenda. Local authorities need to have a realistic monitoring of the current situation; they have a very strong need to have an understanding of the building stock energy consumption in order to be able to draw a strategy of energy efficiency and reduction, set targets and evaluate the impact of actions on energy consumption and $\mathrm{CO}_{2}$ emission reduction.

Interviews undertaken showed that normally municipalities get yearly real energy consumptions of the building stock at the city scale. Most of the time there is a rough segmentation of buildings in three categories: residential, tertiary and industry. Furthermore, data are a few years behind the current year of exploitation, depending on the type of data and the source. They also count on information regarding buildings and households provided by Statistics organisations (NSIs). Such organisations get data through population census and provide them to actors that evaluate the energy consumptions and $\mathrm{CO}_{2}$ emissions.

But most of the local administrations interviewed pointed that to go further they need more detailed data at all levels. The scale of data needed depends on the actions to be carried out. Generally, lower scale is needed by technical actors, and upper scale information is targeting policy and strategy actors. The interviews have revealed that district and block scale is generally sufficient for municipalities because they are unable to target one precise building and they organise strategies at district level. But some municipalities would prefer to have information at building level, because they would have a more precise and reliable evaluation of the consumption. On the other side, going down to the level of the dwelling could enable the public authorities to address particular issues of occupants, but for most actors it is consider as an intrusion into the privacy of citizens.

2. Service providers: Service providers need to communicate their activities and reach the market with their services or products. They firstly need to know the energy strategy of their operation territory. This could help them elaborate clear and relevant services to address the action plan.

Service suppliers have different needs concerning the scale of information needed. Interviews have revealed that they would like data at all types of scales, depending on their core business and their specific projects. Utilities' big investments would require data at regional level. For energy network companies, the needs are at building and district levels, in order to have a more global 
overview. To develop district heating network, operators need to have at least the information at district level and preferably at building level too. Construction companies doing refurbishment works, data at building level is sufficient but they could need data at dwelling level. Some appliances companies would like the information at dwelling level or even more detailed inside the dwelling in order to have a precise analysis of the consumer behaviour and offer them a dedicated service.

3. Citizens: The results of the interviews conducted with representatives of citizens in the three countries (France, Spain and Italy), carried to common and similar conclusions.

Interviewees agreed that, on one hand, the appropriate scale of data for citizens is dwelling/housing scale. This is the usual scale they manage energy data, and seem to be the more understandable for them. Furthermore, citizens are interested to monitor their energy consumption and get precise advices on energy saving measures and potential rehabilitations works to improve energy efficiency of their homes. On the other hand, it was also considered very interesting to provide them information on energy consumption at city scale, as a necessary exercise of local government transparency, but also to include them in a collective effort, to allow citizens to understand how their actions influence city energy consumptions.

Barriers identified regarding the visualization of energy data:

- Reluctance of energy companies to share data. It seems that when companies are more integrated to the local level they are more willing to share data, but in some countries like France, Italy, Spain and the United Kingdom, which have an energy system dominated by few major utilities, cooperation between national utilities and local governments is not easy and many issues have to be tackled.

- The confidentiality of the data is also a very important issue, especially information from the energy consumers for privacy reasons, but also from service providers for competitive reasons. Interviews reflected that generally stakeholders are willing to share the data and information they have if they get benefits in return. They are not willing to share them for free.

- Inaccessibility to existing information on the state of the buildings as IEE database (Buildings Evaluation Report) in Spain. The main problem to access data from a technical point of view comes from the nondigitalisation of data, and the need of processing.

- The lack of energy geo-located information.

\subsubsection{Following-up instrument for action plan}

4. Local Administrations: Mostly all the municipalities consulted through interviews and/or workshops belonged to the Covenant of Mayors network, and have already developed their SEAP. It defines the activities and measures set up to achieve the targets (reduction of energy consumption and $\mathrm{CO}_{2}$ emissions), together with time frames and assigned responsibilities. Every two years the municipality has to report on its SEAP implementation, to check the compliance of the interim results with the foreseen objectives in terms of measures 
implemented and $\mathrm{CO}_{2}$ emission reductions. But tools and/or follow-up instruments for monitoring are lacking.

Barriers identified regarding the follow-up instruments:

- Lack of competences and resources in local administrations.

- Another difficulty is the timeframe of political decisions. There is a mismatch between the political drive of renovation projects and energy efficiency and the timeframe of political decisions.

\subsubsection{Developing a decision-support tool for energy planning (based on the construction of different scenarios)}

5. Local Administrations: Workshops and interviews have showed that defining energy strategies regarding the building stock starts with understanding of the current situation in terms of energy consumption and energy saving potential. It is difficult to have an intuitive knowledge of the building stock, even more for bigger cities. From this starting point, cities need a tool that allows them to design and evaluate different scenarios and alternatives based on a defined set of attributes.

This tool would be very useful to prioritize group of actions according to different criteria as: set a feasible level of investment maximizing energy savings, given an emission saving target find the cost-optimal set of actions or define sets of actions with a balance between short- and long-term payback.

Barriers identified:

- Lack of financial capacity: most of the time energy systems or efficiency investments are driven by lower cost, which is a major source of problems for the future, due to a lack of consistency.

- Lack of employees with strong competences and tools. Some cities need to be supported by external consultants for these tasks.

\subsubsection{Learning from other similar experiences}

6. Local Administrations: The interviews and meetings undertaken with municipalities showed that they are really interested to learn from other cities experiences. Sharing information with other cities implementing similar actions to the ones set out in their action plan can anticipate success or failures what provides margin to straighten up or given up actions, minimizing usefulness investment costs. This way the results obtained by a city would be displayed on a platform, enabling other municipalities to compare the results achieved with their own policies.

Barriers identified:

- There's a lack between public administrations, at the same or different levels. SEAPs from municipalities at the same territory should be aligned to regional policies and vice versa.

\subsubsection{Establishing links with other actors}

Today there is no meeting point between public authorities, service providers and the general public. This meeting point is strongly needed. Both local authorities and service providers are trying to bring service directly to citizens, mainly to raise 
awareness and support actions towards citizens. This has limited success across cities.

7. Local Administrations: They have the duty to orchestrate the development of the energy system on their territory. They do so by directing, more or less closely, the services and products supplied by providers, and by motivating the citizens to have virtuous behaviours regarding their energy consumption. Almost all cities interviewed have information and awareness rising programmes through different communications means. They all have websites addressing issues on energy efficiency of the building stock. In many cases information, studies and recommendations to citizens are deployed also at regional scale.

8. Service Providers: Service providers want to communicate their activities and reach the market with their services or products. They firstly need to know the energy strategy of their operation territory. This would help them elaborate clear and relevant services to address the action plan. But in this regard we have found that sometimes there seem to be some discrepancies and contradictions, as Spanish service providers highlighted a gap between the local plan objectives and its implementation, what does not favour the planning of their core business strategies,

9. Citizens: Finally, the citizens need to have clear information about the challenges of their territory and their building regarding the energy consumption. Awareness raising and consciousness of environmental and economic issues is essential to success. They need to know what the proposed services are in order to make an educated choice among them. Consumers do not know where to go when they are looking for regulations, products and services for energy efficiency. They also demand information on service providers, about their reliability, quality, and performance.

Barriers identified:

- Significant proportion of citizens without access to the internet. Other ways to address citizens are needed: face-to-face, school campaigns, neighbourhood associations, etc.

\subsection{ACCENT tool specific functionalities}

Once the barriers were identified and the needs stated, the ACCENT challenge was how to deal with all of them in a singular tool. A first version of the ACCENT tool is already working to the cities of Paris (Fr), Valencia (Sp), Reggio-Emilia (It) and Ferrara (It). The ACCENT tool is based on a web-platform. The tool provides different and specific user interfaces depending on users' role: local administrator, service provider or citizen. That enables to later deliver functionalities specifically developed to accomplish each user profile needs. The main features and functionalities of the tool have been built around four main functionalities that are described below:

\subsubsection{Mapping functionality}

This interface is based on a GIS map that enables to visualize geo-located energyrelated information regarding the buildings and the city. The information is shown at different scales: building, block, census district, neighbourhood and city level, 
as long as it is available and there are no confidentiality issues. The available data, organized in different layers, is:

- Building categories (municipal buildings, other public buildings, private residential buildings, social housings, tertiary buildings...).

- Construction or last refurbishment date.

- Energy performances of buildings $\left(\mathrm{kWh} /\left(\mathrm{m}^{2} \cdot \mathrm{y}\right)\right)$.

- Energy used for heating, cooling and hot water of buildings.

- Energy consumption of buildings (heating, cooling and hot water...).

The fact that the user can create a selection of buildings and / or districts (by clicking, looking through a search engine or predefined criteria), together with the possibility of overlapping layers with different data, enables them to carry out an urban diagnosis.

\subsubsection{Scenarios functionality}

It starts from a catalogue of predefined actions that could be implemented in buildings and /or districts, in order to reduce energy consumption and GHG emissions in the city. The actions are focused in the improvement of the energy efficiency of buildings and in the implementation of energy systems and renewable energies. Actions incorporate economic and environmental data associated (investment cost, payback period, energy and GHG emissions avoided, etc). The interface allows the user to build new scenarios as a sum of actions that can be selected by type or performance criteria. Through the construction, analysis and comparison of different scenarios, the tool allows taking decisions and defining strategies based on objective and well-founded criteria.

\subsubsection{Action plan functionality}

Local administrations can use the ACCENT tool to construct an energy strategy (SEAP) by means of mapping and scenarios interfaces. Just in case the SEAP was already defined, it can be directly in incorporated in ACCENT. Action plan interface makes possible to manage and monitor the level of achievement of the targeted objectives set out in the action plan. The user can also view and identify trends in energy consumption following the implementation of an action plan. All the data required to report on the plan implementation is calculated and provided by the tool in order to check the compliance of the results.

\subsubsection{Connexion with other cities functionality}

This functionality, specifically designed for cities, enables them to share and benefit from other cities feedback on specific actions. The city's manager of the tool can decide to publish information on the ACCENT network. The information could be regarding a specific action, scenario and/or strategy. Different types of sharing settings have been defined (with a group of other cities, on public website). Comments highlighting successful practices and systems, or difficulties arisen during the implementation can be linked to the published actions in order to work for the common good of energy efficiency along with other cities.

The project is still ongoing and new meetings, interviews and workshops are foreseen to be developed, involving all actors, public administrations, service 
providers and citizens, so that to validate the functionalities and service developed so far and to upgrade the alpha version of the tool to a beta version.

\section{Conclusions}

ACCENT tool, thanks to the adjustment to the common needs and barriers identified at European context, enables local authorities to undertake well supported decisions on energy strategies at different city scales at the same time that permits the monitoring of their energy action plan. In parallel, service providers need energy data as well as information about the localization of the potential clients in order to develop their business strategy. For them it is also important to be aware of the energy strategy of their operation territory. ACCENT provides them with this specific information. Finally, citizens need to know where to go when they are looking for regulations, products and services for energy efficiency. They also demand information on service providers, about their reliability, quality, and performance.

In conclusion, ACCENT should emerge as a meeting point for all the stakeholders involved in the energy strategy. The main challenge is to better adjust the tool to the specific city ecosystem.

\section{Acknowledgements}

The research presented in this paper is partially supported by funds from ClimateKIC, the Europe's largest public-private innovation partnership focused on climate change. The authors gratefully acknowledge the support provided by LGI, together with the consortium partners: ENGIE, NUMTECH, ESRI, ARXIT, EIVP, IVE, INNDEA, ASTER and SINERGIS, especially by: Amira Bentahar from ENGIE.

\section{References}

[1] A. Arteconi, C. M. Bartolini, C. Brandoni and F. Polonara, "Assessment of the impact of local energy policies in reducing greenhouse gas emissions", Environmental Economics and Investment Assessment III, pp. 51-62, 2010.

[2] M. Tadi and M. Vahabzadeh, "Transformation of an urban complex system into a more sustainable form via integrated modification methodology (IMM)", International Journal of Sustainable Development and Planning, vol. 9, no. 4, pp. 514-537, 2014.

[3] European Commission, "Communication from the Commission to the European Parliament, the Council, the European Economic and Social Committee and the Committee of the Regions. A Roadmap for moving to a competitive low carbon economy in 2050 - COM (2011) 112 final”, European Commission, Brussels, 2011.

[4] "Covenant of Mayors for Climate \& Energy", [Online]. Available: http://www.covenantofmayors.eu/index_en.html 
[5] European Commission, How to develop a Sustainable Energy Action Plan (SEAP) - Guidebook, Luxembourg: Publications Office of the European Union, 2010.

[6] H. Bloem, R. Boguslawski, M. T. Borzacchiello, C. Piergiorgio, A. Kona, G. Martirano, I. Maschio and F. Pignatelli, "Location data for buildings related energy efficiency policies", European Commission - Joint Research Centre, Luxembourg, 2015.

[7] F. Ascione, R. F. De Masi, F. de' Rossi, R. Fistola and G. Vanoli, "Energy assessment in town planning: urban energy maps", The Sustainable City VII, pp. 205-216, 2012.

[8] E. Stylianidis, N. Karanikolas and D. Kaimaris, "A Gis for urban sustainability indicators in spatial planning", International Journal of Sustainable Development and Planning, vol. 7, no. 1, pp. 1-13, 2012.

[9] V. Ghomashchi, "Building sustainability through collaborative planning", International Journal of Sustainable Development and Planning, vol. 7, no. 1, pp. 14-25, 2012.

[10] K. Kern and G. Albert, "Governing climate change in cities: modes of urban climate governance in multi-level systems", in Competitive Cities and Climate Change, Milan, 2008. 